\section{Evaluation of Nutrient Solution on the Growth and Yield Per- formance of Organic Lettuce Grown in Vertical Towers}

\section{Dilip Nandwani*, Tariq Muhammad, Sochinwechi Nwosisi and Shahidullah Chowdhury}

Department of Agriculture and Environmental Sciences, College of Agriculture, Human and Natural Sciences, Tennessee State University, Nashville, USA

\begin{abstract}
Vertical farming saves land, space, water, produces no weed, pest or disease issues and ecofriendly. In vertical towers, vegetables can be grown indoors and outdoors all year round in short time with less effort, care and greater harvest yield. The objective of this study was to compare the effect of two nutrient blend solutions on the total yield, fresh weight and dry weight of four varieties of lettuce namely Bibb, Leaf lettuce, oak leaf and red salad. The study was conducted in the fall of 2017 in a hoop house at the Tennessee State University organic farm. Organic seeds were directly planted unto $2.5 \mathrm{~cm}$ rock wool cubes, in an indoor vertical grow tower. Two concentrations of nutrient blend solution A (2:0:0) and B (0-1-3) evaluated. Indoor vertical towers were spaced $0.9 \mathrm{~m}$ from each other. At planting, an initial volume of $400 \mathrm{~mL}$ and $200 \mathrm{~mL}$ of nutrient blend solution $A$ and $B$ was added into 20 gallons of water to fill the tower garden reservoir. Subsequently, Lettuce plants in tower 1 received $400 \mathrm{~mL}$ of the nutrient blend solution while lettuce plants in tower 2 were treated with $200 \mathrm{~mL}$ of nutrient as needed throughout the growing season. Treatment and variety not their interaction had an effect on the growth of the lettuce plants. Yield (fresh wt/g) and dry weight of the Lettuce varieties varied significantly vary from one another. Plant yield was generally higher in the $200 \mathrm{~mL}$ volume. Fresh and dry weight of red salad bowl lettuce variety with $200 \mathrm{~mL}$ volume concentration was found to be significantly higher than that of all other varieties grown
\end{abstract}

*Corresponding author: Dilip Nandwani, Department of Agriculture and Environmental Sciences, College of Agriculture, Human and Natural Sciences, Tennessee State University, Nashville, USA, Tel: +1 6159631897; Email: dnandwan@tnstate.edu

Citation: Nandwani D, Muhammad T, Nwosisi S, Chowdhury S (2019) Evaluation of Nutrient Solution on the Growth and Yield Performance of Organic Lettuce Grown in Vertical Towers. J Agron Agri Sci 2: 014.

Received: October 22, 2019; Accepted: November 12, 2019; Published: November 19, 2019

Copyright: (c) 2019 Nandwani D, et al. This is an open-access article distributed under the terms of the Creative Commons Attribution License, which permits unrestricted use, distribution, and reproduction in any medium, provided the original author and source are credited. with the $400 \mathrm{~mL}$ volume nutrient blend volume. The preliminary study suggest that the grow tower system is a viable alternative to growing lettuce vertically on land and half concentration of nutrient solution (NPK) is optimal for yield performance.

Keywords: Aeroponic; Fresh food; Grow towers; Leafy greens; Mineral concentration; Urban agriculture; Yield

\section{Introduction}

Leafy green vegetables are edible, tasty and provide a lot of nourishment to human beings. There are many widely consumed leafy green vegetables. They come from short-lived herbaceous plants, such as lettuce and spinach. The lettuce (Lactuca sativa) is a cultivated plant of the Asteraceae (daisy) family, with edible leaves that are a usual ingredient of salads. Many varieties of lettuce have been developed with diversity in form, texture, and color. Lettuce is a hardy, cool-weather vegetable that grows best when the average daily temperature is between 16 and $21^{\circ} \mathrm{C}$. When at high temperatures, growth is stunted, the leaves may be bitter and the seed stalk forms and elongates rapidly. Some varieties of lettuce withstand heat better than others; it depends on the variety and the environmental conditions. This plant is one of the most popular vegetables grown in the U.S. Nevertheless, there are not many recommendations for leafy greens grown particularly in organic farming systems, where plants are grown free of chemical use. Recently, the United States Department of Agriculture National Organic Standards Board ruled that organic soilless could be considered as certified organic [1]. The expectation is that this would encourage more people to go into organic production. Here they could skip the three-year wait period required for organic certification of land and employ the aeroponic vertical system for cultivating vegetables, faster and year-round in controlled environments with promising crop yield.

Reports indicate that growing lettuce in an urban tower garden can provide another alternative or avenue of consumption as an act to consume less junk food in the inner cities. Growing vertically in towers is ecofriendly due to efficient system of design, less space and water is used. It would help people live more sustainable lives, save land, water, soil, decrease fossil fuel emission, fertilizer waste [2], as well as pesticide and herbicidal use, and result in an increased yield per unit area of land under cultivation. Aeroponics, a system of vertical farming, is soilless culture such as in a controlled environment like a greenhouse, where roots of plants grown in an enclosed space are bathed regularly with a nutrient rich water solution mix. Some significant benefits to aeroponic vertical towers are higher yields up to $30 \%, 98 \%$ less water, less (up to $90 \%$ space) space and reduced or no insect pest and disease problem compared to traditional growing methods [3-5]. Some farmers worry that using a soilless method in growing crops may yield weaker plants requiring a heavier amount of pesticide and producing less nutrients. However, in a 2014 study [6], it was reported that the yield of leafy greens grown in an aeroponic garden system was found to be higher than those grown in soil. Total phenols, flavonoids and antioxidant content were also observed to be 
higher. Authors saw a $19 \%, 8 \%, 65 \%$, and $21 \%$ more yield was in basil, chard, red kale, and parsley (leafy vegetables) when grown in aeroponic systems.

Aeroponics does not have large water and nutrient requirements because it involves misting the roots of a plant time and again with a definite quantity the plant could use in the most productive way possible through osmosis to provide nutrients to the plant [7]. The constituents of these nutrients which are composed mainly of soluble salts, are determined by how the plant is grown, environmental conditions, growth media, stage of plant development, how the nutrient is applied and so on [8]. With that being said, though lack of plant nutrients can reduce growth and plant quality, an oversupply of nutrients can also be detrimental to plant health [9]. Individuals and companies who carry out research involving preparation of nutrient rich water have used various concentrations in production. It has been reported that aeroponics produces lettuce plants with better root structures than substrate culture or hydroponic systems [10]. Using a horizontal hydroponic system and a vertical farming system in an indoor controlled environment, [11] researchers have discovered that the "vertical farming system produced increased Lettuce yields per unit of growing floor area when compared with the horizontal". In addition, their study revealed a significant decline in the fresh weight of lettuce plants from top to bottom in the vertical system and a general uniform yield in the horizontal system [11].

Currently, literature on how lettuce plants respond to nutrient supply in aeroponic systems is scarce. In this present study, four lettuce varieties were grown in a vertical grow-tower in a hoop house at the organic farm in Nashville. The main objective of this study was to evaluate the yield of four lettuce varieties in grow-towers kept indoors and administered with two concentrations of nutrient blend solutions.

\section{Materials and Methods}

Research trial was conducted in a hoop house at the organic farm, Tennessee State University in Nashville. Seeds of four lettuce varieties (High Mowing Seeds, VT, USA) Bibb, Red salad, Leaf and Oak leaf lettuce were direct seeded unto soilless media, $2.5 \mathrm{~cm}$ rock wool cubes in an indoor vertical grow-towers (Juice Plus, Collierville, TN, USA) in hoop house in October 2017. Vertical towers (each $158 \mathrm{~cm}$ tall on a $0.27 \mathrm{sq}$. $\mathrm{m}$ area) were marked separately based on the nutrient concentration applied (Figure 1). Each tower had five evenly spaced sections. At each height or section was one type of lettuce variety. From top to bottom, sections 1-Bibb, 2-red salad, 3-leaf lettuce, 4-oak leaf lettuce. Each section contained four evenly spaced compartments that held four plants. There were four compartments for each vegetable type in every section per tower. The experiment was replicated in a second tower and both towers were spaced a few feet from each other.

Nutrients were provided using tower garden mineral blend and water with an inbuilt timer and pump to provide the essential nutrients need for proper plant growth and development. The optimal $\mathrm{pH}$ of the nutrient blend solution added to the reservoir was maintained at a mildly acidic $\mathrm{pH}$ of between 5.0 and 7.0. The nitrogen, phosphorous and potassium ratio for mineral solution $\mathrm{A}$ was 2:0:0 while that of mineral solution B was 0-1-3. Nutrient blend solution a (Calcium Nitrate, Iron Sodium EDTA) was made up of $2 \%$ total nitrogen, $1 \%$ Calcium and $0.05 \%$ chelated iron. The ingredients in nutrient blend solution B (Potassium Nitrate, Potassium Sulfate, Magnesium Sulfate, Boric Acid, Copper Sulfate, Manganese Sulfate, Sodium Molybdate, Zinc Sulfate, Phosphoric Acid) was composed of $1.0 \%$ phosphate, $3 \%$ soluble potash, $0.5 \%$ magnesium, $3 \%$ Sulphur, $0.01 \%$ boron, $0.001 \%$ copper, $0.01 \%$ manganese, $0.0005 \%$ molybdenum and $0.005 \%$ zinc. At seed planting, an initial volume of $400 \mathrm{~mL}$ and $200 \mathrm{~mL}$ of nutrient blend solution $\mathrm{A}$ and $\mathrm{B}$ (manufacturer recommended) was required per 20gallons of water. A total volume of 20 gallons needed to be added to each tower to fill the tower garden reservoir. The flow rate was regulated by turning a dial on the pump clockwise or anticlockwise either to minimum or maximum levels respectively. Care was taken when increasing the flow rate towards maximum levels to prevent the nutrient solution from making contact with the cap to avoid a nutrient leak. Subsequently, Lettuce plants in tower 1 received $400 \mathrm{~mL}$ of the nutrient blend solution while lettuce plants in tower 2 were treated with $200 \mathrm{~mL}$ of nutrient solution per 20 gallons of water as needed throughout the growing season as recommended by the manufacturer. Generally, a full tank reservoir (20 gallon in volume) lasted for about two weeks and we prepared nutrient blend water mix to add to reservoir when required. We ensured however to keep enough nutrient solution so that at least half of the tank reservoir was filled with water, the pump was always submerged in nutrient solution.

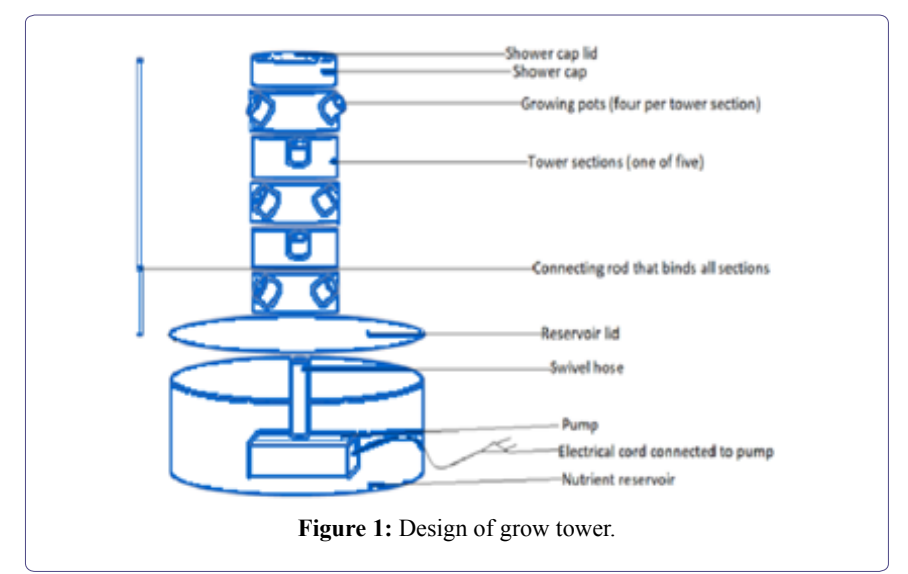

Lettuce varieties were grown and maintained according to the national organic program standards [12]. Plants were observed during various stages of growth and pictures taken. After eight weeks, plants were harvested. The total fresh weight per plant was recorded for each tower. Plants were placed inside an oven set at $60-65^{\circ} \mathrm{F}$ for seventy-two hours. Dry weight of plants was measured, and data recorded. Data was collected on fresh and dry weight of lettuce varieties. Analysis of variance (Two-way ANOVA) was conducted by Graphpad 8.0 (To determine multiple comparisons among treatments, varieties and their interactions, Tukey's Honestly Significant Difference (HSD) post-hoc test were used.

With this efficient system of design, it occupies less space and consumes less water, which ultimately is earth friendly. The vertical tower is usually purchased together with rockwool cubes that are placed in growing pots, mineral nutrient solutions, a pump and a timer amongst others.

\section{Results}

Plant growth in two nutrient solution treatments was different in vertical towers (Figure 2). 


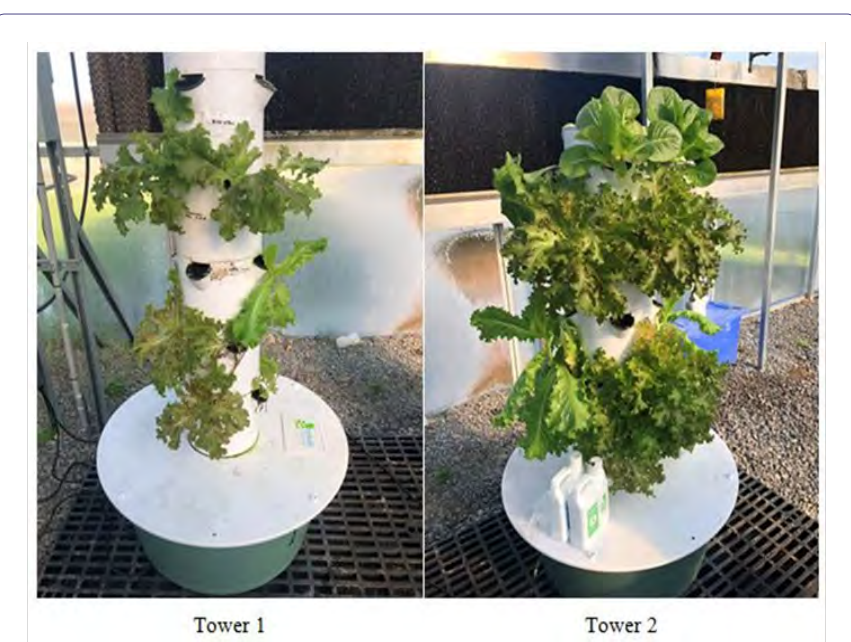

Figure 2: Tower garden showing lettuce varieties eight weeks of planting. Left to right: Tower $1(400 \mathrm{~mL}$ nutrient blend concentration); Tower $2(200 \mathrm{~mL}$ nutrient blend concentration). From top to bottom sections: 1-Bibb, 2-Red salad, 3-Leaf lettuce, and 4-Oak leaf lettuce.

Upon observation, using two different quantities to treat each tower the results show the significant effect the solution has as it relates to these leafy greens in a hydroponic vertical tower system (Table 1). The effect of different varieties and treatments on the fresh and dry weight of the lettuce plants and not the interaction between them was significant $(\mathrm{p}<0.05)$.

\begin{tabular}{|c|c|c|c|c|c|c|}
\hline \multirow{2}{*}{ Sources } & \multicolumn{3}{|c|}{ Fresh wt. (g/plant) } & \multicolumn{3}{c|}{ Dry wt. (g/plant) } \\
\cline { 2 - 7 } & DF & F-value & p-value & DF & F-value & p-value \\
\hline Variety & 3 & 5.68 & 0.0272 & 3 & 7.57 & 0.0133 \\
\hline Treatment & 1 & 40.51 & 0.0004 & 1 & 44.79 & 0.0003 \\
\hline Variety*Treatment & 3 & 3.30 & 0.0874 & 3 & 3.61 & 0.0735 \\
\hline Errors & 7 & & & 7 & & \\
\hline
\end{tabular}

Table 1: ANOVA table partitioning the sources of variance for fresh and dry weight of Lettuce varieties (g/plant).

$\mathrm{p}<0.05$ is statistically significant at 5 percent significant level.

Overall, total yields (Fresh and dry weight) of the Red Salad Bowl Lettuce variety, though not significantly different from Bibb and leaf lettuce, differed significantly from the Oak leaf variety (Figure 3). For the $200 \mathrm{ml}$ nutrient blend treatment, the Oak leaf lettuce $(14.05 \mathrm{~g})$ was the least yielding in terms of fresh weight/g and Red Salad Bowl $(62.55 \mathrm{~g})$ was the highest. The Bibb lettuce $(1 \mathrm{~g})$ on the other hand, had the lowest fresh wt/g yields of all the varieties tested when treated with the $400 \mathrm{ml}$ nutrient blend solution while Red Salad Bowl had the highest $(9.7 \mathrm{~g})$.

Per plant yield (Fresh wt./g) was significantly higher in the red salad lettuce $(62.55 \mathrm{~g})$ grown with the $200 \mathrm{~mL}$ nutrient blend when compared with the Bibb (1g), red salad bowl $(9.7 \mathrm{~g})$, Leaf $(9.55 \mathrm{~g})$ and oak leaf $(3.15 \mathrm{~g})$ lettuce varieties produced with the $400 \mathrm{~mL}$ nutrient blend concentration (Tower 1) (Figure 3). At the same 200mL nutrient blend concentration (Tower 2), red salad bowl lettuce yield $(62.55 \mathrm{~g})$ was only significantly higher than oak leaf lettuce $(14.05 \mathrm{~g})$. Its yield did not vary significantly from the Bibb $(37.3 \mathrm{~g})$ and leaf $(38.35 \mathrm{~g})$ lettuce yield at the $400 \mathrm{ml}$ nutrient blend concentration. Similar result was obtained in for the dry weight of lettuce varieties in both towers (Figure 3). The exception was that the dry weight of leaf lettuce yield $(2.05 \mathrm{~g})$ in tower $2(200 \mathrm{~mL})$ was significantly higher than the oak leaf lettuce $(0.8 \mathrm{~g})$ in tower $1(400 \mathrm{~mL})$, and no significant difference observed between their fresh weights.

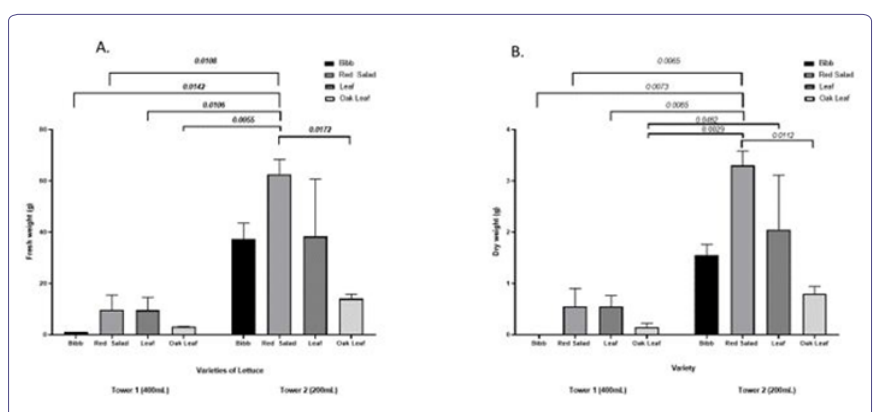

Figure 3: Main effects of different lettuce varieties and nutrient blend volume on fresh and dry weight of lettuce.

\section{Discussion}

The results of this study as shown, show a clear display of the impact the use of two different quantities of mineral A and B solution had on the two towers. There was one variable that drastically changed the experiment, and it was the quantity of mineral solution that was given to both towers. The reason for this being was to make a comparison between two different treatments which would allow us to see the effect the two solutions would have on the lettuce if any. Tower 1 was treated with $400 \mathrm{~mL}$ of mineral solution while tower 2 was treated with $200 \mathrm{~mL}$ of mineral solution. Even though tower 1 $(400 \mathrm{~mL})$ had more mineral solution treatment than tower $2(200 \mathrm{~mL})$, from the very beginning of the transplanting until the harvesting of both towers, tower $1(400 \mathrm{~mL})$ showed very little growth and slow growth as well as progress. Then it was observed that as harvest time approached, the growth of tower $2(200 \mathrm{~mL})$ created an amassed gap in its growth as compared to tower $1(400 \mathrm{~mL})$. Like previous studies [13], more variability was found between plants with less concentration of nutrient solution due to greater competition between plants when nutrients are limited. Less variability was observed between plants with more nutrient solution. At first, skepticism came as to if the solutions applied were either more beneficial or more detrimental to the overall well-being of the lettuce varieties as in the hypothesis it was thought to be that it would be the exact opposite. The results as far as the dry weight and fresh weight of both towers show the effect twice the recommended quantity [14] of mineral blend nutrient solution $(400 \mathrm{~mL})$ as opposed to $200 \mathrm{~mL}$ ) treatment for a aeroponic vertical tower has on the growth of plants, specifically lettuce and how several lettuce varieties respond differently. It was clear that there was a significant difference that was highly prominent in this experiment in relation to the different treatments that were performed on both towers. In aeroponics, the plant root is provided a large amount of oxygen and water in a saturated environment which aids the roots metabolism and speeds up its growth [7] and as such the environmental conditions that are necessary for photosynthesis to occur, including the availability of rich nutrients water solution might have influenced food supply to the plant roots [15] in tower $2(200 \mathrm{~mL})$. However, as observed in tower $2(400 \mathrm{~mL})$ when micronutrients build up to extreme quantities in plants, this could cause a lot of damage to the cells in plants due to the release of reactive oxygen species leading to a decline in plant 
Citation: Nandwani D, Muhammad T, Nwosisi S, Chowdhury S (2019) Evaluation of Nutrient Solution on the Growth and Yield Performance of Organic Lettuce Grown in Vertical Towers. J Agron Agri Sci 2: 014.

- Page 4 of 6 -

growth and quality [9]. Some studies [16] have reported that reduced fresh and dry weight of lettuce plants in aeroponic systems may be due to higher nitrate levels in the plant or higher flow rates which leads to root stress from root crushing and subsequently gives rise to a decline in nutrient levels. In agreement with our findings, some studies have reported that excess nutrients provided to the plant roots reduces lettuce fresh yields and growth in aeroponic systems due to osmotic stress [17]. The authors [17] found that excessive nutrients caused a reduction in leaf area and stomatal conductance, however they did not observe a harmful build-up of ions in the leaves or damage to the electron transport chain. Likewise, extremely high or low Electrical Conductivity (EC) has been found to cause nutrient stress and reduce plant growth and quality in Brassicaceae species [18] in a hydroponic system. Higher EC reduces the ability of a plant to absorb nutrients by raising osmotic pressure, unwanted nutrients and release of these nutrients into the surrounding environment as pollutants [18]. The optimal electrical conductivity which varies with crop type, measures the concentration of electrolytes and salt in a solution, is proportional to the quantity of ions in the root area, and is influenced by the condition of the plant's environment $[19,20]$. Further studies are needed to discover other methods such as discovery of new technologies and real estate development to help grow the lettuce in a faster and more efficient manner in contrast with what we have done in this experiment.

\section{Conclusion}

First research trials suggest that growth and yield of lettuce varieties at $400 \mathrm{~mL}$ nutrient concentration was inconsequential and at this concentration, the Bibb lettuce variety barely produced. The red salad bowl lettuce at the $400 \mathrm{~mL}$ produced significantly higher yields than the oak leaf lettuce at the same $400 \mathrm{~mL}$ concentration and more than all varieties tested with $200 \mathrm{~mL}$ nutrient blend solution concentration. The leaf lettuce dry weight at $400 \mathrm{~mL}$ nutrient blend solution concentration also differed significantly from the Oak Leaf lettuce at the same concentration. The result of this study which shows the yield of lettuce can be grown successfully in grows tower system. Future trials on other leafy green vegetables at lower strength of the nutrient solution or single varieties of lettuce at both concentrations of nutrient solutions are suggested. Another idea of experiment that can be interpreted conclusively is to apply different nutrients or solution to the aeroponic vertical tower to see if results would be the same or different.

\section{Acknowledgment}

Funding support for this study was from cooperative extension grant to DN. Authors would like to thank Joshua Ibukun Raji for his contributing to manuscript review, the Organic agriculture research program team for field assistance.

\section{Author Contribution}

Conceptualization, methodology, resources and funding was provided by Dilip Nandwani.; Tariq Muhammad and Shahidullah Chowdhury carried out the Investigation and Data Curation; Dilip Nandwani and Shahidullah Chowdhury carried out Project Administration and Supervision; Formal Analysis and visualization was conducted by Sochinwechi Nwosisi and Tariq Muhammad; Writing - Original Draft Preparation was by Tariq Muhammad; Writing - Review \& Editing was by Sochinwechi Nwosisi; All authors validated the experiment.

\section{Conflicts of Interest}

The authors declare no conflict of interest.

\section{References}

1. Fassler J, Cox K (2017) It's the end of "organic" as we know it. New food economy, NewYorkCity.

2. Cavasos R, Domenghini J (2016) Comparison of two hydroponic tower systems for lettuce production. Eastern Kentucky University, Department of Agriculture, Richmond, Kentucky.

3. NASA-National Aeronautics and Space administration (2006) Progressive plant growing has business blooming. In: Spin off. Editors- Originating technology/NASA. Publications and graphics department NASA Center for Aerospace Information (CASI). Pg no: 64-67.

4. Utami Sri, Darmanto, Jayadi Rachmad (2012) Vertical gardening for vegetables. Acta Horticulturae. Pg no: 195-202.

5. Nandwani D, Gunther D (2015) Urban Agriculture: vertical organic farming. Tennessee State University Cooperative extension, College of Agriculture, Human and Natural Sciences. Pg no: 1-4.

6. Chandra S, Khan S, Avula B, Lata H, Yang MH, et al., (2014) Assessment of total phenolic and flavonoid content, antioxidant properties, and yield of aeroponically and conventionally grown leafy vegetables and fruit crops: A comparative study. Evid Based Complement Alternat Med 253875.

7. Lakhiar Imran Ali, Jianmin Gao, Tabinda Naz Syed, Farman Ali Chandio, Noman Ali Buttar (2018) Modern plant cultivation technologies in agriculture under controlled environment: A review on aeroponics. Journal of plant interactions 13: 338-352.

8. Guang-jae L, Bo-goo K, Tae-il K, Tae-jung K, Jin-han K (2007) Tomato hydroponics in Korea. Fruit, Vegetables and Cereal Science and Biotechnology 1: 104-109.

9. Morgan JB, Connolly EL (2013) Plant-Soil Interactions: Nutrient Uptake. Nature Education Knowledge 4: 2.

10. Li Qiansheng, Xiaoqiang Li, Bin Tang, Mengmeng Gu (2018) Growth responses and root characteristics of lettuce grown in aeroponics, hydroponics, and substrate culture. Horticulturae 4: 35.

11. Touliatos D, Dodd IC, McAinsh M (2016) Vertical farming increases lettuce yield per unit area compared to conventional horizontal hydroponics. Food and energy Security 5: 184-191.

12. USDA (2015) National organic standards board. United States Department of Agriculture Washington, D.C., USA.

13. Jug T, Slamic B (2016) Lettuce growth in extreme conditions. Journal of Food and Agriculture 28: 398-401.

14. Blank T (2017) Growing guide: Tower garden by juice plus. Pg no: 1-14.

15. Kawasaki Y, Matsuo S, Kanayama Y, Kanahama K (2014) Effect of rootzone heating on root growth and activity, nutrient uptake, and fruit yield of tomato at low air temperatures. J Jpn Soc Hortic Sci 83: 295-301.

16. Khater Elsayed (2015) Comparison between hydroponic and aeroponic systems for lettuce production. The $20^{\text {th }}$ Annual Conference of Misr Soc. of Ag. Eng., Egypt.

17. Albornoz Francisco, J Heinrich Lieth (2015) Over fertilization limits lettuce productivity because of osmotic stress. Chilean J Agric Res 75: 284290. 
Citation: Nandwani D, Muhammad T, Nwosisi S, Chowdhury S (2019) Evaluation of Nutrient Solution on the Growth and Yield Performance of Organic Lettuce Grown in Vertical Towers. J Agron Agri Sci 2: 014.

- Page 5 of 6 •

18. Ding X, Jiang Y, Zhao H, Guo D, He L, et al (2018) Electrical conductivity of nutrient solution influenced photosynthesis, quality, and antioxidant enzyme activity of pakchoi (Brassica campestris L. ssp. Chinensis) in a hydroponic system. PLoS Oneg 13: 0202090.

19. Sonneveld C, Voogt W (2009) Plant nutrition of greenhouse crops. Springer, New York, USA.
20. Bot JL, Adamowicz S, Robin P (1998) Modelling plant nutrition of horticultural crops: A review. Sci Hortic 74: 47 -82. 


\section{Hit}

Journal of Anesthesia \& Clinical Care

Journal of Addiction \& Addictive Disorders

Advances in Microbiology Research

Advances in Industrial Biotechnology

Journal of Agronomy \& Agricultural Science

Journal of AIDS Clinical Research \& STDs

Journal of Alcoholism, Drug Abuse \& Substance Dependence

Journal of Allergy Disorders \& Therapy

Journal of Alternative, Complementary \& Integrative Medicine

Journal of Alzheimer's \& Neurodegenerative Diseases

Journal of Angiology \& Vascular Surgery

Journal of Animal Research \& Veterinary Science

Archives of Zoological Studies

Archives of Urology

Journal of Atmospheric \& Earth-Sciences

Journal of Aquaculture \& Fisheries

Journal of Biotech Research \& Biochemistry

Journal of Brain \& Neuroscience Research

Journal of Cancer Biology \& Treatment

Journal of Cardiology: Study \& Research

Journal of Cell Biology \& Cell Metabolism

Journal of Clinical Dermatology \& Therapy

Journal of Clinical Immunology \& Immunotherapy

Journal of Clinical Studies \& Medical Case Reports

Journal of Community Medicine \& Public Health Care

Current Trends: Medical \& Biological Engineering

Journal of Cytology \& Tissue Biology

Journal of Dentistry: Oral Health \& Cosmesis

Journal of Diabetes \& Metabolic Disorders

Journal of Dairy Research \& Technology

Journal of Emergency Medicine Trauma \& Surgical Care

Journal of Environmental Science: Current Research

Journal of Food Science \& Nutrition

Journal of Forensic, Legal \& Investigative Sciences

Journal of Gastroenterology \& Hepatology Research

Journal of Gerontology \& Geriatric Medicine
Journal of Genetics \& Genomic Sciences

Journal of Hematology, Blood Transfusion \& Disorders

Journal of Human Endocrinology

Journal of Hospice \& Palliative Medical Care

Journal of Internal Medicine \& Primary Healthcare

Journal of Infectious \& Non Infectious Diseases

Journal of Light \& Laser: Current Trends

Journal of Modern Chemical Sciences

Journal of Medicine: Study \& Research

Journal of Nanotechnology: Nanomedicine \& Nanobiotechnology

Journal of Neonatology \& Clinical Pediatrics

Journal of Nephrology \& Renal Therapy

Journal of Non Invasive Vascular Investigation

Journal of Nuclear Medicine, Radiology \& Radiation Therapy

Journal of Obesity \& Weight Loss

Journal of Orthopedic Research \& Physiotherapy

Journal of Otolaryngology, Head \& Neck Surgery

Journal of Protein Research \& Bioinformatics

Journal of Pathology Clinical \& Medical Research

Journal of Pharmacology, Pharmaceutics \& Pharmacovigilance

Journal of Physical Medicine, Rehabilitation \& Disabilities

Journal of Plant Science: Current Research

Journal of Psychiatry, Depression \& Anxiety

Journal of Pulmonary Medicine \& Respiratory Research

Journal of Practical \& Professional Nursing

Journal of Reproductive Medicine, Gynaecology \& Obstetrics

Journal of Stem Cells Research, Development \& Therapy

Journal of Surgery: Current Trends \& Innovations

Journal of Toxicology: Current Research

Journal of Translational Science and Research

Trends in Anatomy \& Physiology

Journal of Vaccines Research \& Vaccination

Journal of Virology \& Antivirals

Archives of Surgery and Surgical Education

Sports Medicine and Injury Care Journal

International Journal of Case Reports and Therapeutic Studies

Submit Your Manuscript: http://www.heraldopenaccess.us/Online-Submission.php 